\title{
Exnovation of Low Value Care: A Decade of Prostate-Specific Antigen Screening Practices
}

\author{
Julie Bynum, MD, MPH, ${ }^{*+}$ Honor Passow, PhD, ${ }^{*}$ Donald Carmichael, MDiv, ${ }^{*}$ and \\ Jonathan Skinner, $P h D^{\ddagger \$ l}$
}

OBJECTIVES: To examine prostate-specific antigen (PSA) screening practice change in subgroups of men defined in guidelines and in various regions and to identify factors associated with change in screening practices.

DESIGN: Observational study using serial cross-sections, 2003 to 2013.

SETTING: National fee-for-service Medicare.

PARTICIPANTS: Men aged 68 and older eligible for prostate cancer screening.

MEASUREMENTS: National PSA screening practices in men aged 68 and older from 2003 to 2013 and change in regional screening rates in men aged 75 and older.

RESULTS: The PSA screening rate in men aged 68 and older was $17.2 \%$ in $2003,22.3 \%$ in 2008 , and $18.6 \%$ in 2013 ( $\mathrm{p}<.001$ for all differences); rates ended slightly lower than rates in 2003 only in men 80 and older. Racial disparities in screening became less pronounced over this period. In men aged 75 and older, change in regional screening rates varied widely, with absolute rates growing by 15 per 100 enrollees in some areas and declining by the same amount in others. Areas with high social capital, a measure associated with diffusion of new ideas, were more likely to decline; malpractice intensity and managed care penetration had no effect.

CONCLUSION: Studying Medicare enrollees over time, we found little reduction in PSA screening and even increases according to race and in some regions. The heterogeneous changes across regions suggest that consistent reduction in the use of low-value care may require change strategies that

From the *Department of Medicine, School of Medicine, University of Michigan, Ann Arbor, Michigan; 'Institute of Healthcare Policy and Innovation, University of Michigan, Ann Arbor, Michigan; ${ }^{*}$ Dartmouth Institute for Health Policy and Clinical Practice, Geisel School of Medicine, Dartmouth College, Hanover, New Hampshire; ${ }^{\S}$ Department of Economics, Dartmouth College, Hanover, New Hampshire; and the "National Bureau of Economic Research, Cambridge, Massachusetts.

Address correspondence to Julie Bynum, 300 North Ingalls, Rm 933, Ann Arbor, MI 48109. E-mail: bynumju@med.umich.edu

DOI: $10.1111 /$ jgs.15591

go beyond evidence and guidelines to include monitoring and feedback on performance. J Am Geriatr Soc 67:29-36, 2019.

Key words: low-value care; prostate cancer screening; Medicare

$\mathrm{T}$ here is a "pervasive asymmetry in human psychology" that makes it harder for healthcare workers to give up old clinical practices than to adopt new ones, even when they are revealed to provide low value. ${ }^{1}$ Across disciplines, there is increasing interest in the idea of "exnovation," or the process by which practitioners turn away from an existing practice or process. $^{2-5}$ Screening for prostate cancer using the prostatespecific antigen (PSA) is an important example of evolution of practice in response to emerging scientific evidence.

After years of debate, in March 2009, two randomized controlled trials provided evidence that screening for prostate cancer using the PSA test offered at best modest benefits, particularly in aged 70 and older. ${ }^{6,7}$ In 2010 and 2011, systematic reviews concluded that PSA screening provides no significant reduction in prostate cancer or overall mortality. 8,9 One concluded that the harms were frequent and moderately severe, ${ }^{8}$ and the other found little evidence of harms. ${ }^{9}$

Before this period, guidelines for PSA screening repeatedly changed (Figure 1), converging on the notion that the value of PSA screening is low. For example, when proposing its latest update, ${ }^{10-14}$ the U.S. Preventive Services Task Force (USPSTF) stated there is "a small net benefit for men ages 55 to 69 years, [but] the balance of benefits and harms in men remains close." ${ }^{15}$ The guidelines are also nuanced, requiring complex estimations of benefit:harm ratios in subgroups of men who may not be well represented in trials. For example, the USPSTF and the American Urological Association have consistently recommended against screening men with a limited life expectancy, sometimes naming a specific age cutpoint, ${ }^{16-21}$ and because of the greater risk of 


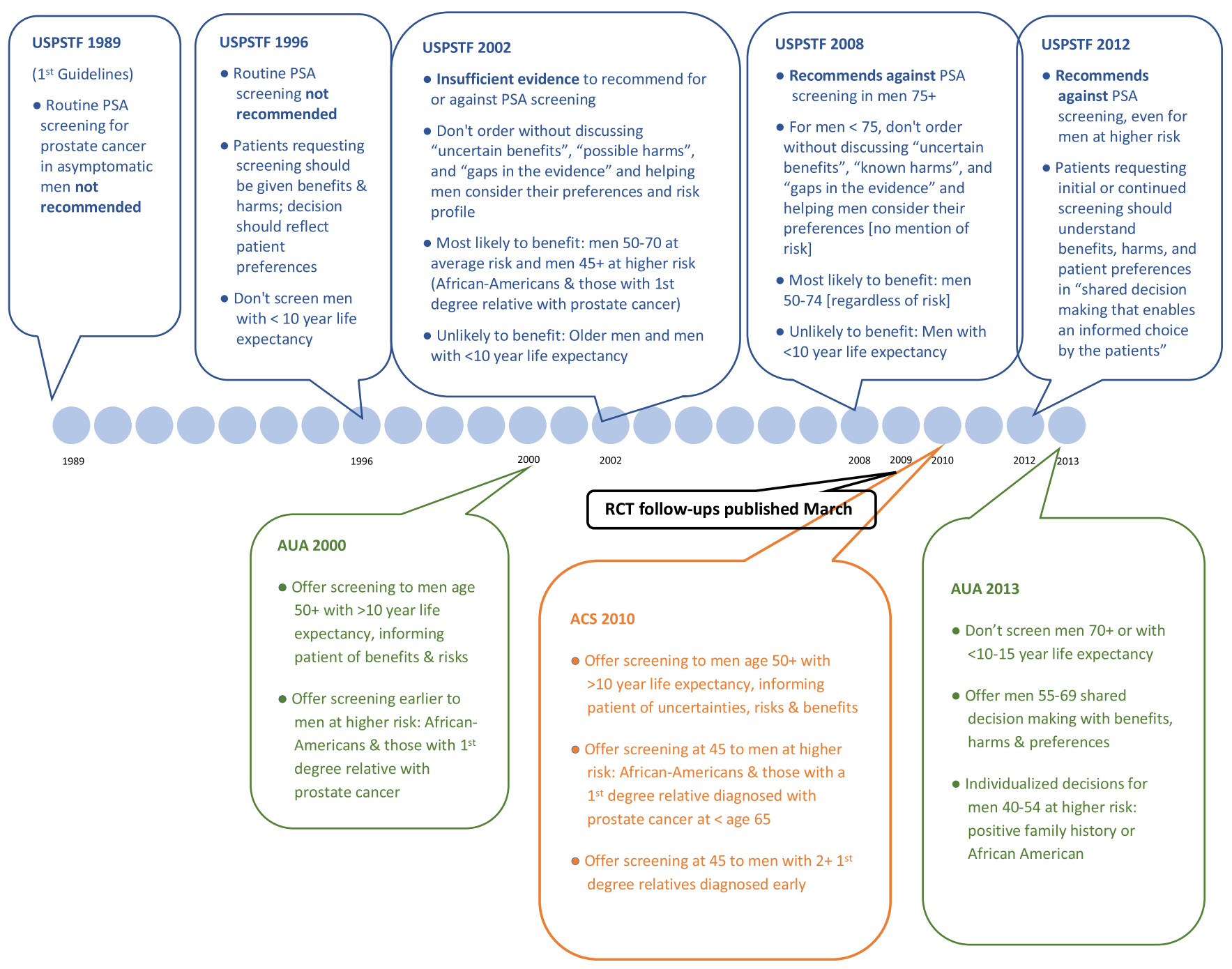

Figure 1. A history of clinical practice guidelines and evidence pertaining to prostate-specific antigen screening of asymptomatic men, including all U.S. Protective Services Task Force guidelines, publication of pivotal evidence, and selected other guidelines.

prostate cancer in black men, some guidelines recommend initiating screening earlier. ${ }^{17,19,22}$

Changing guidelines were on a background of widely varying regional screening practices. Given disparate screening practices, it is not clear that practice change, even for the oldest men, for whom guidelines agreed, would occur uniformly across markets. Examining what happened in clinical practice over this period of evidence and guideline change provides an opportunity to understand the process of exnovation of low-value services.

Using PSA screening, we aimed to understand which factors influence practice change during a period when a decline in service use would be expected. First, we focused on national PSA screening in men aged 68 and older with fee-for-service Medicare from 2003 to 2013 and examine the influence of guidelines by assessing changes in likelihood of screening associated with factors directly mentioned in guidelines. Second, we focused on practice change across U.S. hospital referral regions (HRRs) for men aged 75 and older - for whom guidelines have been in agreement - to test whether practice variation declines and what contextual factors are associated with greater decline. We hypothesized that guidelines and the practice environment would influence the degree to which practitioners and patients would reduce their use of an existing practice in the face of converging evidence regarding effectiveness.

\section{METHODS}

\section{Setting and Participants}

This observational cohort study of older men was drawn from a $20 \%$ national sample of the fee-for-service Medicare population during each of 5 years: 2003, 2006, 2008, 2010, and 2013. Men were eligible if they were enrolled in Medicare Parts A and B and not managed care. Because PSA claims (identified using Common Procedural Terminology codes ${ }^{23}$ ) do not distinguish screening from diagnosis, we applied an algorithm previously validated to exclude men with any history of prostate disease (cancer, surgery, high PSA) during the prior 3 years or symptoms suspicious of cancer from visit diagnoses in the 3 months before a PSA test. ${ }^{24,25}$ Men had to be aged 68 and older to accommodate the disease-free interval. Men with no ambulatory visits 
were excluded because it is unlikely that PSA levels tested during hospitalization were for screening.

Information on age and race was obtained from the Medicare summary file; information on covariates was obtained also using claims information. Covariates included dual eligibility for Medicaid, 10-year life expectancy as an aggregate measure of illness that aligns with guideline recommendations, and visit patterns. We created predicted 10 -year mortality risk scores. Logistic regression predicted 10-year mortality risk for the 2003 cohort - whose death status was known at the end of 2012- using these explanatory variables: baseline age, race, Medicaid status, ambulatory visits, skilled nursing facility stays, and Elixhauser comorbidity conditions. We used a random $50 \%$ sample to derive our prediction model and the other half to validate it (c-statistic $=0.79$ for both cohorts) ${ }^{26}$ Mean predicted mortality ranged from 0.27 in the lowest quintile to 0.96 in highest quintile. We included number and continuity of ambulatory visits, which have been shown to influence whether a person receives preventive services or low-value care. $^{27,28}$ We used the Continuity of Care Index, a computation of dispersion in visits across the number of unique physicians, categorized into tertiles. ${ }^{29}$

HRRs to represent regional healthcare and were characterized according to factors shown previously to influence physician behavior: screening practice norms ${ }^{25}$ penetration of managed care, ${ }^{30,31}$ malpractice activity, ${ }^{32}$ and social capital. ${ }^{33}$ We represent the underlying PSA screening practice norm with the proportion of men aged 68 and 69 screened because they were the only age group in our data who met guidelines for potential benefit. ${ }^{34,35}$ Malpractice activity, which differs between areas, ${ }^{32}$ was measured according to state according to physician payment amounts in 2003, from which we created HRR measures weighted by the fraction of each state's residents. To account for potential spill-over effects from practicing in an area where population management strategies are prevalent, ${ }^{30,31}$ we measured Medicare Advantage enrollment. Social capital measures the multidimensional social environment that influences behavior $^{36}$ and has been associated with uptake of innovations in- and outside medicine. ${ }^{33} \mathrm{~A}$ county-level social capital index is available for 2005 and 2009 based on the number of civic, religious, and sports organizations per capita; census response rate; voter turnout in presidential elections; and number of nonprofit organizations per capita. ${ }^{37}$ We weighted the county measures to the HRR using Missouri Census Data Center Geographic Correspondence Engine 2010 data. $^{38}$

\section{Statistical Analysis}

Differences in the characteristics of the men in each cohort year were tested using descriptive statistics. The large sample resulted in statistical significance even when differences were small. National trends are reported as crude screening rate according to subgroup. The associations between age and race adjusted for other factors including region in 2013 were compared with 2003. To do so, the probability of having a PSA test was modeled using Poisson regression in a hierarchical framework adjusting for regional effects using a conditional likelihood approach. The Poisson model was chosen because it allows estimation of relative risk when event probability is high. ${ }^{39}$

Regional screening rates for men aged 75 and older in each year were calculated using random-effects regression, adjusting for population age, race, and predicted mortality. The adjusted and crude rates were highly correlated (correlation coefficient $=0.99$ ), so we report crude rates. We tested whether variation in practice declined over time by comparing the coefficient of variation across HRRs from 2013 to 2003. We then modeled whether 2003 area characteristics predicted absolute change in screening rate between 2003 and 2013. This study had institutional review board approval from the Geisel School of Medicine. Analysis was performed using SAS version 9.4 (SAS Institute, Inc., Cary, NC) and Stata version 14.1 (Stata Corp., College Station, TX).

\section{RESULTS}

\section{Study Cohorts}

Supplementary Figure S1 and Supplementary Table S1 show details of cohort creation and characteristics each year. Approximately $40 \%$ of men each year were excluded because of prostate disease, leaving approximately 1 million men in each study-year eligible for a screening PSA. Over time, mean age remained unchanged, but there were small shifts in racial distribution, probability of death, Medicaid enrollment, outpatient visits, and continuity. Penetration of managed care increased from $16 \%$ to $35 \%$.

\section{Change in Screening According to Subgroups of Men}

National PSA screening rates for men aged 68 and older were $17.2 \%$ in 2003 , rose to $22.3 \%$ in 2008 , and declined to $18.6 \%$ in 2013 (Figure 2). This trend was similar for all race and age groups, including those aged 90 and older. The screening rate in 2013, when the new trial and guidelines had been out for 1 to 5 years, remained $1.4 \%$ higher than the screening rate in 2003. The 2013 screening rate was slightly lower than in 2003 for men aged 80 to $84(13.5 \%$ vs $14.1 \%$ p < .001), 85 to $89(9.2 \%$ vs $10.3 \%$, $\mathrm{p}<.001)$, and 90 and older $(5.8 \%$ vs $6.3 \%$, p <.001). At the beginning of the period, rates were lower for black and Hispanic men than for white men but rose faster until 2008 such that by 2013 there was little if any racial difference.

Bivariate analysis of proportions screened according to individual characteristics is shown in Supplementary Table S1. Using multivariable regression analysis controlling for region, we found independent effects of age, predicted mortality, race, dual eligibility, visits, and continuity, although their influence changed over time. Figure 3 shows these results graphically by comparing each factor's strength of association with likelihood of PSA screening in 2003 with the strength of association in 2013 (full model in Supplementary Table S2). Predicted 10-year mortality was consistently associated with lower likelihood of screening, but age independent of life expectancy became important over time. For example, in 2003, only men aged 90 and older were at lower risk of being screened, but in 2013, lower risk of screening was found beginning at age 75 . This 


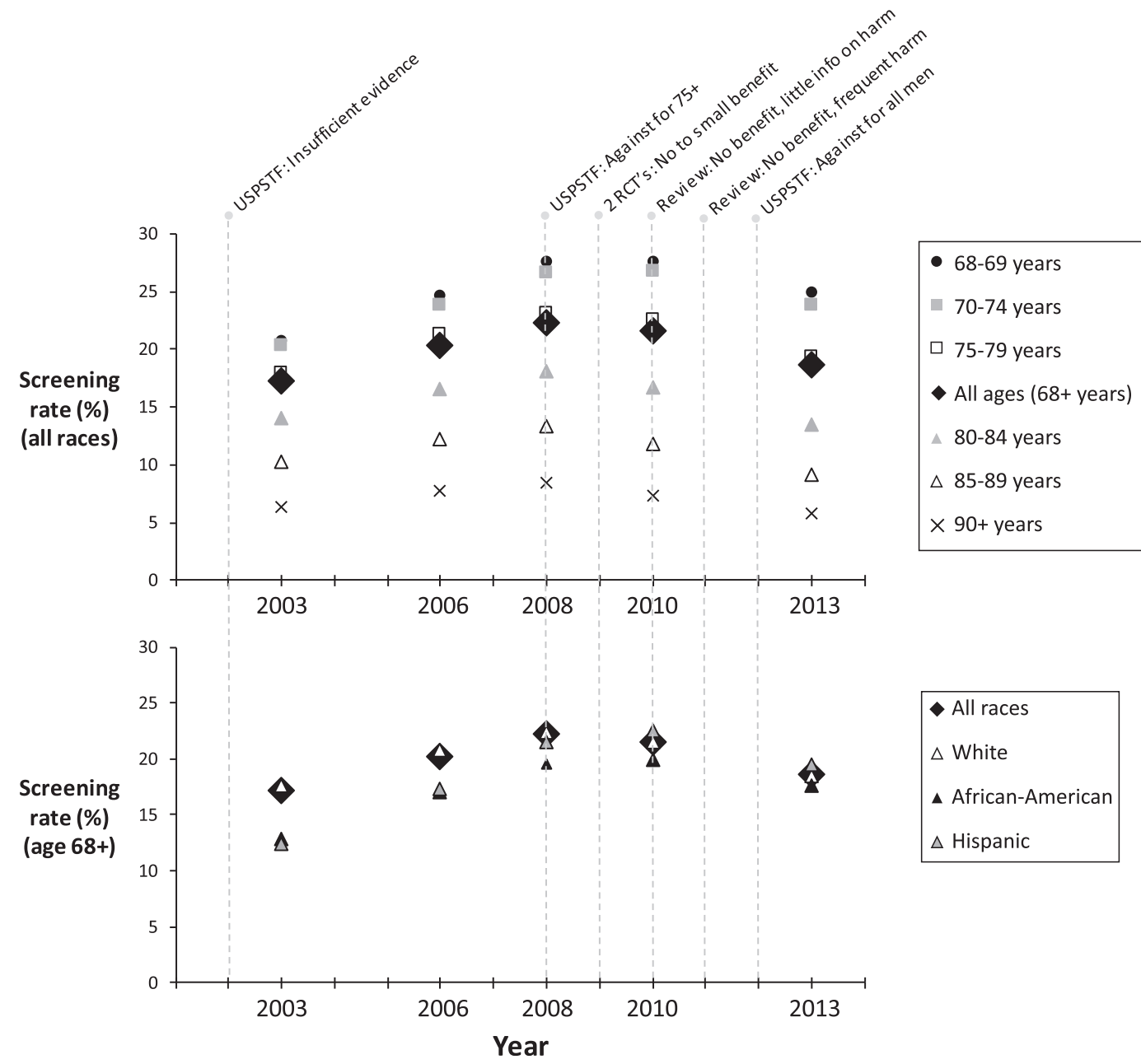

Figure 2. U.S. national rates for prostate-specific antigen (PSA) screening according to age and race for 2003 to 2013, when evidence and clinical guidelines changed regarding PSA screening.

finding suggests that age alone has become a deciding factor in whether to screen.

The relationship between race and ethnicity and likelihood of screening changed over time. Black race (relative risk $(\mathrm{RR})=0.81,95 \%$ confidence interval $(\mathrm{CI})=0.78-0.84$ ) and Hispanic ethnicity $(\mathrm{RR}=0.86,95 \% \mathrm{CI}=0.78-0.94)$ were associated with lower screening rates in 2003, but the strength of association decreased for blacks $(\mathrm{RR}=0.91$, $95 \% . I=0.87-0.94)$ and became insignificant for Hispanics $(\mathrm{RR}=0.93,95 \% \mathrm{CI}=0.87-1.00)$ by 2013. As a result, racial and ethnic disparities in screening rates declined during this period. Dual-eligible enrollees, who were less likely to be screened in 2003 ( $\mathrm{RR}=0.66,95 \% \mathrm{CI}=0.63-0.70)$, were not so in 2013 ( $\mathrm{RR}=0.93,95 \% \mathrm{CI}=0.82-1.02$ ). Finally, no change was seen in the relationship between visit patterns and screening; having more ambulatory visits was consistently associated with greater likelihood of screening and greater continuity with slightly less likelihood of screening.

\section{Change in Screening Across Regions}

In 2003, HRR rates of PSA screening varied widely for men aged 75 and older, from $2.3 \%$ in Contra Costa County, California, to $42.1 \%$ in Sun City, Arizona; the median was
$14.1 \%$, with a coefficient of variation of 0.43 . The coefficient of variation rose slightly to 0.49 in 2013 , demonstrating greater practice variation.

Change in screening rates in men aged 75 and older across regions was in an unanticipated direction, with nearly as many HRRs experiencing a rise in screening as experiencing a decline (Figure 4). Although the median HRR declined by 1.5 percentage points, the screening rate in some HRRs increased by as much as 15 percentage points, whereas others declined by 15 . Some HRRs declined in every interval studied (42 HRRs, $14 \%$ ), but increased in 14 after the trials were released. Higher level of screening at baseline and higher social capital predicted decline in screening. High proportion minority population predicted rising rates (Supplementary Table S3). Other population characteristics, malpractice activity, and penetration of managed care were not consistently associated with change.

\section{DISCUSSION}

From 2003 to 2013, questions about the value of PSA screening were reflected in guideline changes that new evidence later supported. PSA screening in men aged 68 and older, which had been rising, fell gradually from 2009 to 2013, after the trials were released, but still ended slightly 


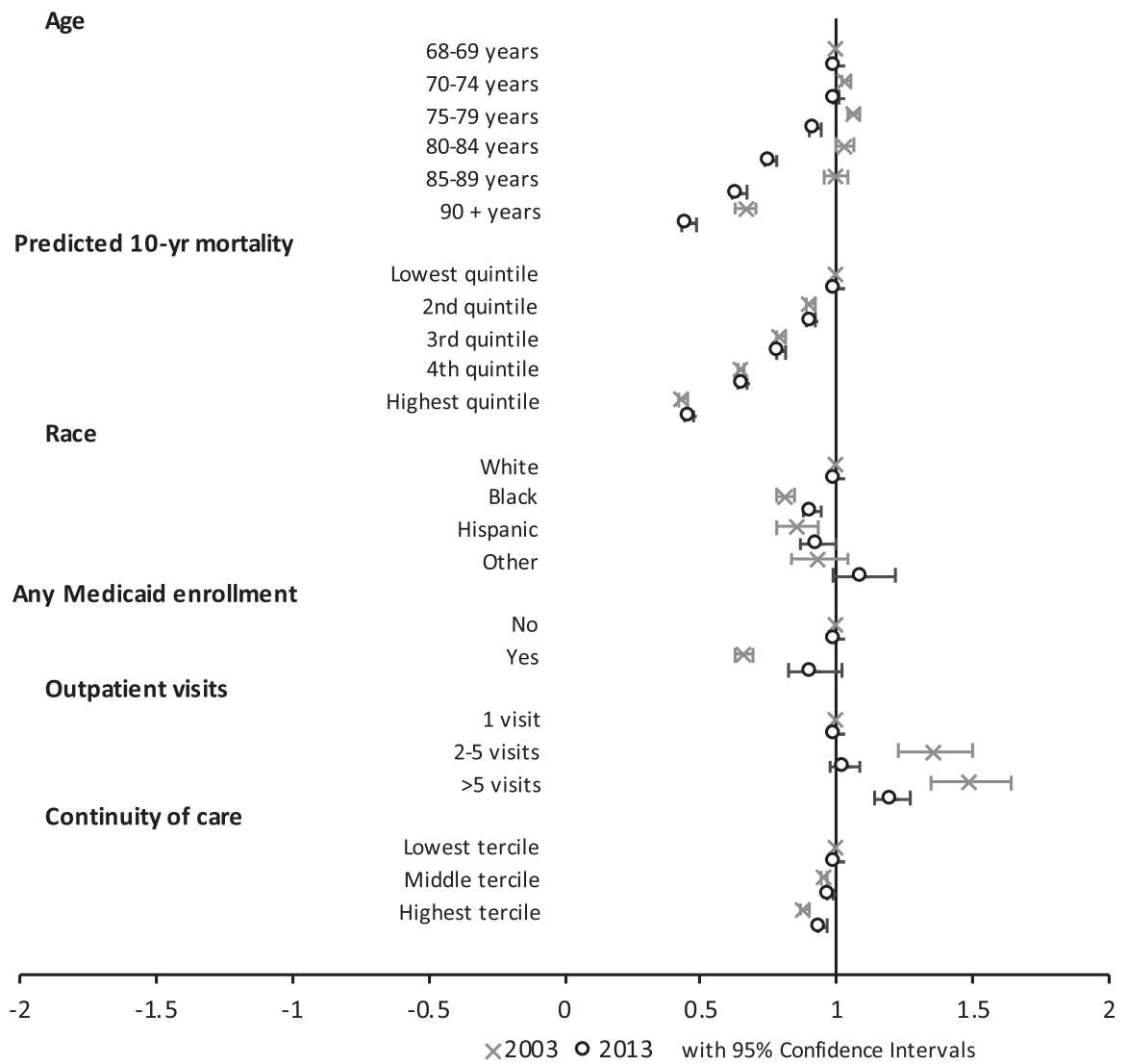

Figure 3. Adjusted risk of prostate-specific antigen (PSA) Screening for men aged 68 and older associated with each individual factor in 2003 and 2013.

higher in 2013 than in 2003. More surprisingly, we observed an increase in regional variation for screening in men aged 75 and older, suggesting more rather than less divergence in clinical practice. Screening rates for men aged
75 and older increased during this period in nearly as many HRRs as they decreased. Despite these variations, we found evidence that guidelines had aggregate effects for some subgroups, such as a reduction in screening in those aged

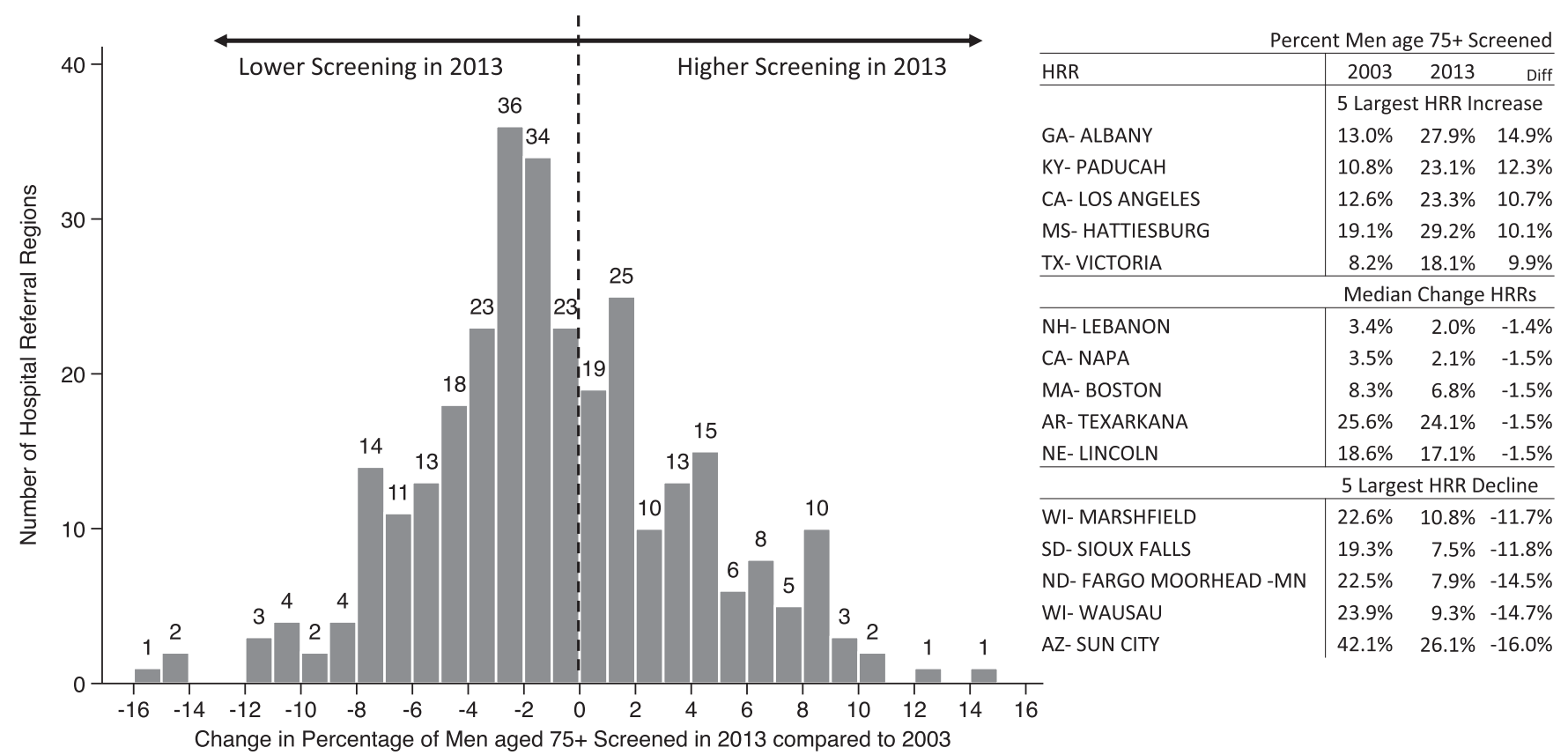

Figure 4. Variation across hospital referral regions in absolute change between 2003 and 2013 in prostate-specific antigen screening rate in men aged 75 and older. 
75 and older, and an attenuation of racial and ethnic disparities, but those effects are modest compared with the large variations in regional patterns of use.

Two recent reviews indicated that screening rates have declined, ${ }^{40,41}$ but these reviews synthesized heterogeneous data including self-reports (which have been shown to be biased ${ }^{42}$ ), small areas, and different time periods. Two studies that used objective screening measures spanning 2008 to 2012 showed the same pattern as ours, ${ }^{43,44}$ whereas others using shorter time periods or limited areas showed only declining rates. ${ }^{45-50}$ We found no prior studies of change in PSA screening rates in response to guidelines according to race, although two studies found no differential effect of race when examining referral or stage of disease. ${ }^{51,52}$ Our study has the advantage over these prior studies of using consistent measures of PSA testing well before and after evidence change, with a large enough sample to examine heterogeneity of change across subgroups of men and across areas. Unlike prior studies, by taking a longer view, we found mixed evidence of the influence of guidelines: some minor changes within named subgroups, but no large, consistent shifts in practice toward less screening.

We did not expect to find that PSA screening in men aged 75 and older would increase in some regions, which makes the analysis of contextual factors particularly important. Our hypotheses were that factors might have affected greater decline, such as average age in the region, income, racial distribution, and contextual factors including malpractice activity, prevalence of integrated healthcare, and social capital. We found that average age and income were not important, although higher minority population predicted greater increase in screening, possibly due to efforts to reduce disparities in access to care or in response to concerns about higher prostate cancer risk. I light of the observed increase in some areas, malpractice intensity was not a significant predictor, nor was managed care penetration, but higher social capital was. Social capital suggests that there is something in the local culture that may make it more receptive to let go of an existing practice. A similar association has been found for uptake of new technologies such as beta blockers for acute myocardial infarction but has not previously been shown in association with exnovation. ${ }^{33}$

The modest reduction in screening rates in men aged 75 and older, who are more likely to experience harm than benefit from PSA screening, warrants asking why the evidence and converging guidelines have done so little to reduce low-value care. One reason could be discomfort with age-based cut-points when age is only a proxy for life expectancy. Life expectancy was the most important predictor of screening in our data. With release of the age-based recommendations, age alone was increasingly used as a deciding factor. It is likely that the main challenge that patients and providers face hinges less on the decision to use age or life expectancy and more on having the time necessary to make a well-informed decision that includes mortality risk and time-to-benefit considerations. ${ }^{53}$

Primary care providers, many of whom agree with the guidelines ${ }^{54}$, are key players in changing screening practice because of their role in cancer prevention and frequent contact, ${ }^{55}$ but the evidence suggests that patients are informed infrequently and that providers have not changed their practice much. ${ }^{43,46,55}$ Change strategies that rely on encouraging shared decision-making without providing systematic support for the time those patient-provider interactions require are unlikely to lead to wholesale change in use of low-value care. Moreover, lack of feedback about a provider's current performance precludes the ability to evaluate and change one's practice. Performance reports regarding indicated services, such as diabetes testing, are common but reporting on avoidance of a service that is not recommended occurs less often. Our results highlight the need, as alluded to previously, ${ }^{56}$ to pay as much attention to evaluating changes in our practice when incorporating new evidence as on developing and evaluating the evidence itself.

What can we learn generally from this study about reducing the use of an existing practice? First, when guidelines recommend discontinuing a service, the response may be slower than when adding or increasing use is recommended. Second, when guidelines change multiple times and require a nuanced decision process, they may not meet with uniform adoption. During the early period of observation, when guidelines indicated doubt about PSA value while trials were pending, rates of screening rose. One explanation could be that publicity about the controversial recommendations led to greater attention and hence use. Third, fragmented physician contact increased the likelihood of a man having PSA screening. Greater continuity may relate to greater patient-physician trust when making a difficult decision to reduce use. Lastly, although the social capital of an area is not in itself modifiable, awareness of this community factor allows policy and clinical leaders to anticipate where adoption may be rapid and other areas where a more active change strategy may be needed.

There are several limitations of the study. We cannot discern who is driving the change in practice: patients or providers, but there were no changes in Medicare coverage of PSA screening, which eliminates patient cost as a potential explanation. ${ }^{57}$ This limitation raises the important point that an additional approach to changing low-value practice is through consumer-directed efforts. Second, our study is restricted to the fee-for-service Medicare population, so results may not be generalizable to the managed care setting.

\section{Summary}

Screening for prostate cancer serves as an excellent case study of how exnovation occurs, or does not, when evidence and guidelines suggest use should decline. Studying Medicare enrollees over time, we found little reduction and even increases according to race and in some regions. The presumption that better clinical evidence and guidelines alone will lead to a significant reduction in use of potentially low-value care may be overly optimistic, especially when the recommendations require nuanced application. Messaging that prioritizes potential benefit in one subgroup risks overdiagnosis and overtreatment when that message is generalized. In addition to careful guideline messaging, attaining better evidence-driven, personcentered care may require more-systematic approaches that include local monitoring of and feedback on behaviors we aim to reduce. 


\section{ACKNOWLEDGMENTS}

This study was funded by National Institutes of Health Grants U01-AG046830 and P01-AG019783.

Conflict of Interest: Skinner is an investor in Dorsata, Inc. and a consultant to Sutter Health. None of the other authors have financial or personal conflicts of interest associated with this study.

Author Contributions: Study concept and design: Bynum, Passow, Skinner. Acquisition of subjects and data: Bynum, Skinner. Analysis and interpretation of data: Bynum, Passow, Carmichael, Skinner: Preparation and approval of manuscript: Bynum, Passow, Carmichael, Skinner.

Sponsor's Role: The sponsor had no role in the design, methods, data collections, analysis, or preparation of paper.

\section{REFERENCES}

1. Roman BR, Asch DA. Faded promises: The challenge of deadopting lowvalue care. Ann Intern Med 2014;161:149-150.

2. de Hoop E, Pols A, Romijn H. Limits to responsible innovation. J Responsible Innov 2016;3:110-134.

3. Hermwille L. En Route to a Just Global Energy Transformation? 2017 (online). Available at http://library.fes.de/pdf-files/iez/13453.pdf. Accessed on September 12, 2018.

4. Heyen DA. Working Paper: Governance of Exnovation: Phasing out NonSustainable Structures; 2017 (online). https://www.oeko.de/fileadmin/ oekodoc/WP-Exnovation-EN.pdf.

5. Bardach E. Policy termination as a political process. Policy Sci 1976;7: 123-131.

6. Schroder FH, Hugosson J, Roobol MJ et al. Screening and prostate-cancer mortality in a randomized European study. N Engl J Med 2009;360: $1320-1328$.

7. Andriole GL, Crawford ED, Grubb RL et al. Mortality results from a randomized prostate-cancer screening trial. N Engl J Med 2009;360: 1310-1319.

8. Ilic D, O'Connor D, Green S et al. Screening for prostate cancer: An updated Cochrane systematic review. BJU Int 2011;107:882-891.

9. Djulbegovic M, Beyth RJ, Neuberger MM, et al. Screening for prostate cancer: Systematic review and meta-analysis of randomised controlled trials. BMJ 2010;341:c4543.

10. Moyer VA. Screening for prostate cancer: U.S. Preventive Services Task Force Recommendation Statement. Ann Intern Med 2012;157:120-134.

11. Hamdy FC, Donovan JL, Lane JA et al. 10-Year outcomes after monitoring, surgery, or radiotherapy for localized prostate cancer. N Engl J Med 2016; 375:1415-1424.

12. Wilt TJ, Brawer MK, Jones KM et al. Radical prostatectomy versus observation for localized prostate cancer. N Engl J Med 2012;367:203-213.

13. Barocas DA, Alvarez J, Resnick MJ et al. Association between radiation therapy, surgery, or observation for localized prostate cancer and patientreported outcomes after 3 years. JAMA 2017;317:1126-1140.

14. Chen RC, Basak R, Meyer A-M et al. Association between choice of radical prostatectomy, external beam radiotherapy, brachytherapy, or active surveillance and patient-reported quality of life among men with localized prostate cancer. JAMA 2017;317:1141-1150.

15. Bibbins-Domingo K, Grossman DC. The US Preventive Services Task Force 2017 draft recommendation statement on screening for prostate cancer: An invitation for review and comment. JAMA 2017;317:1949-1950.

16. U.S. Preventive Services Task Force. Guide to Clinical Preventive Services, 2nd Ed. Alexandira, VA: International Medical Publishing, 1996.

17. U.S. Preventive Services Task Force. Screening for prostate cancer: Recommendation and rationale. Ann Intern Med 2002;137:915-916.

18. U.S. Preventive Services Task Force. Screening for prostate cancer: U.S. Preventive Services Task Force recommendation statement. Ann Intern Med 2008;149:185-191

19. American Urological Association. Prostate-specific antigen best practice policy. Oncology 2000;14:267-286.

20. Green KL, Albertsen PC, Babaian RJ et al. Prostate specific antigen best practice statement: 2009 update. J Urology 2009;182:2232-2241.

21. Carter HB, Albertsen PC, Marry M et al. Early detection of prostate cancer: AUA guideline. J Urol 2013;190:419-426.
22. Wolf AMD, Wender RC, Etzioni RB et al. American Cancer Society guidelines for the early detection of prostate cancer: Update 2010. CA Cancer J Clin 2010;60:70-98.

23. Centers for Medicare and Medicaid Services. HCPCS-General Information; April 2, 2016 (online). Available at https://www.cms.gov/medicare/coding/ medhcpcsgeninfo/index.html.

24. Walter LC, Bertenthal D, Lindquist $\mathrm{K}$ et al. PSA screening among elderly men with limited life expectancies. JAMA 2006;296:2336-2342.

25. Bynum J, Song Y, Fisher E. Variation in prostate-specific antigen screening in men aged 80 and older in fee-for-service medicare. J Am Geriatr Soc 2010;58:674-680.

26. Giancristofaro RA, Salmaso L. Model performance analysis and model validation in logistic regression. Statistic. 2003;63:375-396.

27. Heflin MT, Oddone EZ, Pieper CF et al. The effect of comorbid illness on receipt of cancer screening by older people. J Am Geriatr Soc 2002;50: $1651-1658$.

28. Romano MJ, Segal JB, Pollack CE. The association between continuity of care and the overuse of medical procedures. JAMA Intern Med 2015;175: $1148-1154$.

29. Bice TW, Boxerman SB. A quantitative measure of continuity of care. Med Care 1977;15:347-349.

30. Baicker K, Chernew M, Robbins J. The spillover effects of Medicare managed care: Medicare advantage and hospital utilization. J Health Econ 2013; 32:1289-1300.

31. Baker L. Managed care spillover effects. Annu Rev Public Health 2003;24: 435-456.

32. Baicker K, Fisher ES, Chandra A. Malpractice liability costs and the practice of medicine in the Medicare program. Health Aff 2007;26:841-852.

33. Skinner J, Staiger D. Technology adoption from hybrid corn to betablockers. In: Berndt ER, Hulten CR, eds. Hard-to-Measure Goods and Services: Essays in Honor of Zvi Griliches. Chicago, IL: University of Chicago Press, 2007, pp 545-570.

34. Tsodikov A, Gulati R, Heijnsdijk EAM et al. Reconciling the effects of screening on prostate cancer mortality in the ERSPC and PLCO trials. Ann Intern Med 2017;167:449-455.

35. Qaseem A, Barry MJ, Denberg TD et al. Screening for prostate cancer: A guidance statement from the Clinical Guidelines Committee of the American College of Physicians. Ann Intern Med 2013;158:761-769.

36. Putnam RD. Bowling alone: America's declining social capital. J Democr 1995;6:65-78.

37. Rupasingha A, Goetz SJ, Freshwater D. The production of social capital in U.S. counties. J Socio Econ 2006;35:83-101.

38. Missouri Census Data Center. MABLE/Geocorr 12, Version 1.2: Geographic Correspondence Engine; 2012 (online). Available at http//mcdc.missouri. edu/websas/geocorr12.html Accessed November 2016.

39. McNutt L-A, Wu C, Xue X et al. Estimating the relative risk in cohort studies and clinical trials of common outcomes. Am J Epidemiol 2003;157: 940-943.

40. Eapen RS, Herlemann A, Washington SL et al. Impact of the United States Preventive Services Task Force "D" recommendation on prostate cancer screening and staging. Curr Opin Urol 2017;27:205-209.

41. Fleshner K, Carlsson S, Roobol MJ. The effect of the USPSTF PSA screening recommendation on prostate cancer incidence patterns in the USA. Nat Rev Urol 2017;14:26-37.

42. Rauscher GH, Johnson TP, Cho YI et al. Accuracy of self-reported cancerscreening histories: A meta-analysis. Cancer Epidemiol Biomarkers Prev 2008;17:748-757.

43. Cohn JA, Wang CE, Lakeman JC et al. Primary care physician PSA screening practices before and after the final U.S. Preventive Services Task Force recommendation. Urol Oncol 2014;32:41.e23-41.e30.

44. Aslani A, Minnillo BJ, Johnson B et al. The impact of recent screening recommendations on prostate cancer screening in a large health care system. J Urol 2014;191:1737-1742.

45. Ross JS, Wang R, Long JB et al. Impact of the 2008 US Preventive Services Task Force recommendations to discontinue prostate cancer screening among male Medicare beneficiaries. Arch Intern Med 2012;172:1601-1602.

46. Goodwin JS, Jaramillo E, Yang L et al. Is anyone listening? Variation in PSA screening among providers for men $75+$ before and after United States Preventive Services Task Force recommendations against it: A retrospective cohort study. PLoS One 2014;9:e107352.

47. Howard DH, Tangka FK, Guy GP et al. Prostate cancer screening in men ages 75 and older fell by 8 percentage points after task force recommendation. Health Aff 2013;32:596-602.

48. Lee SY, Friderici J, Stefan MS et al. Impact of the 2008 U.S. Preventive Services Task Force Recommendation on frequency of prostate-specific antigen screening in older men. J Am Geriatr Soc 2014;62:1912-1915. 
49. Ong MS, Mandl KD. Trends in prostate-specific antigen screening and prostate cancer interventions 3 years after the U.S. Preventive Services Task Force recommendation. Ann Intern Med 2017;166:451-452.

50. Zeliadt SB, Hoffman RM, Etzioni R et al. Influence of publication of US and European prostate cancer screening trials on PSA testing practices. J Natl Cancer Inst 2011;103:520-523.

51. Perez TY, Danzig MR, Ghandour RA et al. Impact of the 2012 United States Preventive Services Task Force statement on prostate-specific antigen screening: Analysis of urologic and primary care practices. Health Serv Res 2015;85:85-91.

52. Barocas DA, Mallin K, Graves AJ et al. Effect of the USPSTF Grade D recommendation against screening for prostate cancer on incident prostate cancer diagnoses in the US. J Urol 2015;194:1587-1593.

53. Lantz PM, Ubel PA. The use of life expectancy in cancer screening guidelines. Moving with caution from model-based evidence to evidence-based guidelines. J Gen Intern Med 2005;20:552-553.

54. Volk RJ, Linder SK, Kallen MA et al. Primary care physicians' use of an informed-decision making process for prostate cancer screening. Ann Fam Med 2013;11:67-74.
55. Hoffman RM, MP C, Zikmund-Fisher BJ et al. Prostate cancer screening decisions: Results from the National Survey of Medical Decisions. Arch Intern Med 2009;169:1611-1618.

56. Vickers AJ. Prostate cancer screening: Time to question how to optimize the ratio of benefits and harms. Ann Intern Med 2017;167:509-510.

57. American Cancer Society. Insurance coverage for prostate cancer screening; April 3, 2016 (online). https://www.cancer.org/cancer/prostate-cancer/earlydetection/insurance-coverage.html.

\section{SUPPORTING INFORMATION}

Additional Supporting Information may be found in the online version of this article.

Supplementary Appendix S1: Supporting Information. 